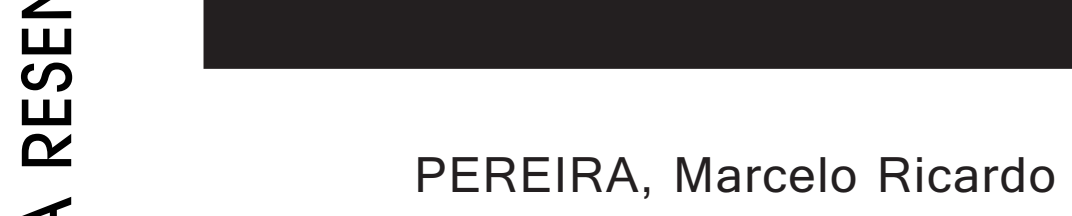

\title{
A impostura do mestre
}

\author{
Belo Horizonte, MG: Argumentum, 2008, 213p.
}

\section{Marcia Regina Fogaça}

A

impostura do mestre de Marcelo Ricardo Pereira, resultado de sua tese de doutorado desenvolvida na Faculdade de Educação da Universidade de São Paulo, proporciona-nos de entrada o prazer de ler o Prefácio de Leandro de Lajonquière, o qual adianta e indica a ideia central do texto que nos aguarda: trata-se de analisar as raízes inconscientes do ponto de engodo em torno do qual giram as lamúrias cotidianas dos professores - miséria neurótica decorrente da negação, do não querer saber da impossibilidade da educação, tal como Freud a preconiza e Lacan a lê.

Tais lamúrias nos são apresentadas pelo autor no "Prelúdio", no qual, como saídas do script de um filme, suas palavras se transformam em imagens: pode-se "ver" a sala dos professores, acompanhar seu olhar percorrendo, identificando e interpretando ícones, signos, alegorias, imagens da escola e da educação. Pode-se também "ouvir" as lamúrias dos ali presentes em relação à desvalorização do magistério, nas quais um significante soa mais alto - respeito, ou sua ausência - nessa sala de professores tão semelhante a tantas outras. A diferença desta é que houve aí uma escuta que levou a um novo

Doutoranda do Programa de Pós-graduação em Educação da Universidade de São Paulo (USP). 
sentido para o ouvido: que "na esfera educacional, o dilema do declínio docente parece se alinhar ao dilema do declínio da imago do pai". E foi partindo, ou, tirando partido da escuta das lamúrias dos professores que Pereira formulou sua tese: que o mestre só o é provisoriamente, como um "deus de prótese": destacável, provisório e suplente.

Do escutado - que há um certo alinhamento entre o declínio docente e o declínio da imago do pai - Pereira formula sua hipótese inicial: "mestres sempre serão pequenos tiranos escarnecidos", a partir da qual irá desenvolver sua tese mediante um preciso e rigoroso desenrolar de ideias.

É possível que, num primeiro momento, o leitor pense tratar-se de mais um texto que trabalha em favor da restituição simbólica do pai e dos que são tradicionalmente a ele alinhados - deus e o mestre -, uma vez que o livro inicia com a análise da genealogia dos vínculos sociais e da constituição da sociedade moderna, esta última sendo realizada através da "via régia" para sua exploração: os tabus e fenômenos totêmicos. Para tanto, o autor recorre às duas incontornáveis obras de Freud, Totem e tabu e Moisés e o monoteísmo, esforçando-se para apontar nelas uma radicalidade que só é possível de ser alcançada através de uma leitura via Lacan. Leitura essa que, em alguns momentos, excede o texto lacaniano.

Uma das consequências tiradas pelo autor da leitura de Freud, em primeira instância, é a mesma de tantos outros que delas se ocuparam, qual seja, há que responder à injunção que nos induz à pergunta/enigma que ele mesmo se fez: "o que é um pai?".

Valendo-se de Lacan, Pereira propõe que, no momento seguinte ao ato mítico, parricida e canibal do pai da horda primeva, há a fundação conjunta de duas ordens: a fraterna, marcada pela materialidade, pela mundanalidade e pelo paganismo, e a paterna, deificada, onde um "deus-conceito, abstrato e transcendente" surge como forma posterior à do totem enquanto representante do pai: "daí o axioma de que toda forma de religião é uma 'nostalgia' não apaziguada do pai..." (p. 39). Nostalgia manifesta na inclinação humana à veneração e à sujeição, materializada na transformação gradual da ordem fraterna numa sociedade patriarcal que perpetua o espírito e a vontade do pai. Portanto, certo declínio da virilidade, assim como uma marca de fragilidade, estão presentes na origem e apresentam-se como condição de existência de tal ordem e de tal sociedade, uma vez que a virilidade está condicionada a uma perda original relativa à exceção 
mítica do pai da horda - único a se inscrever no matema ${ }^{1}$ lacaniano que traduz tal exceção. A sexuação masculina estabelece-se como democracia, o que exige renúncia das pulsões em favor de uma igualdade ilusória entre todos seus membros e institui uma "terceira ordem" em torno do impossível do desejo de ocupar o lugar de poder do "ao menos um".

Tal terceira ordem, como aponta Pereira citando Freud (1939), se presentifica no discurso pedagógico como moralidade: "quando a sociedade, de uma maneira geral, estabelece o bom e o mau, o virtuoso e o vicioso, o disciplinado e o travesso, exige-se sempre a mesma coisa, a saber, uma renúncia pulsional sob a pressão da autoridade que 'substitui o pai”' (p. 43). Autoridade que, por um lado, merece admiração, sujeição e temor e, por outro, é desmascarada como impostora, uma vez que a função paterna não pode ser encarnada. Essa ambivalência é a mesma que, com relação ao pai do mito, manifesta a nostalgia do pai e a vinculação de sacralidade com mestria. A etimologia da palavra sagrado - algo em que não se pode tocar - é recuperada para pensar tal vinculação: sacratu, do latim sacer que deriva consecrare que significa tanto sagrado ou consagrado, como também, execrável, infame, detestável. Assim, “o mestre ao ser sacralizado, assim como o pai da horda, não somente torna-se intocável, santo e profundamente respeitado, como também se torna, ele mesmo, detestável e abominável”, donde, "a desautorização parece ser inerente à própria concessão de poder" (p. 44).

Em Moisés e o monoteísmo, Pereira encontra, para compor seu mestre impostor, aquele que funda a ilusão do amor comum - mestre que ama a todos igualmente - motor das instituições sociais e da ética republicana moderna. Mestre que, segundo Freud, foi o pai verdadeiro por fornecer leis e um sistema simbólico a seu povo/filhos. Pai, mestre, governante, ou, pais, mestres, governantes: encarnações de desejo das massas, destino da humanidade que, por nascer imatura, necessita de cuidados, amor e orientação, enfim, de mestres educadores que respondam à nostalgia de um guia.

A transformação do pai em mestre se dá através de um colocar-se entre o gozo do poder e a interdição, sendo sua estratégia revivificar a função do pai do qual é o porta-voz. Porém, tal função o supera enquanto pessoa e, quando se esquece disso, quando encarna o pai, é desmascarado, lembrado pelos discípulos de que não passa de um impostor. Assim, professores que se arvoram como mestres são atores de uma tragédia: ao encarnar a lei são denunciados, desautorizados, po- 
rém, se não o fazem a ordem humana está em risco. Impasse que a topologia lacaniana clareia ao deslocar o acento da função interditora do pai para a linguagem: é por ser falante que o humano não pode gozar da exceção, uma vez que a linguagem repete e interdita o ato gozoso do suposto "ao menos um”.

No capítulo 3, "Do pai ao mestre", Pereira faz a teoria freudiana trabalhar no sentido de sua tese, trazendo o discurso pedagógico atual como uma constante queixa em relação à falta de tudo que diz respeito a algo que pode ser traduzido como autoridade paterna ou masculina, e que resulta em ausência de limites dos supostos privados de pai. Para além das questões que se inscrevem no registro "biográfico", há as que se inserem nas "leituras psicopedagógicas das linhas freudianas" nas quais um Édipo "pedagógico" busca centrar, unificar e aprisionar o sujeito entendido como maturação biológica ou psicogenética. Porém, nos diz o autor, o maior problema dessas leituras é a anulação do debate sobre o sujeito moderno representado, fundamentalmente, por Marx, Nietzsche e Freud, que o colocam, respectivamente, como sujeito histórico, como um sujeito definido em termos de vontade de servidão e de domínio, e como ausência de consciência de si e de seus desejos. A ausência de tal debate levou a que a imagem de um pai lesivo e aterrorizante, foi sendo amansada pela pedagogia: "existem os pais fracos, os pais 'bananas', os submissos, os abatidos, os enfermos, trôpegos etc. O discurso pedagógico parece fecundo em adjetivar os pais que as próprias escolas 'fabricam', ao amansá-los e evocá-los como necessários." (p. 69).

Recolocando a questão freudiana sobre o pai, Pereira retoma a tradução lacaniana do pai como metáfora ${ }^{2}$ e explora a noção de falo, para além de significante do desejo, como um quarto elemento que Lacan introduz na estrutura edipiana ternária freudiana, porém, como 'ex-sistente' à estrutura, sendo assim, em termos de função, correlato ao Nome-do-Pai: ambos são interventores lógicos, "ex-sistentes" e possibilitam o descolamento do desejo em relação a objetos reais e imaginários. $\mathrm{Na}$ sequência, faz um encadeamento lógico que culmina numa questão-chave de sua tese: o Nome-do-Pai como quarto elemento ex-sistente, inserido na triangulação edípica e no enodamento borromeano, leva a que este passe do singular para o plural. Édipo é um dos possíveis nomes do pai, assim como os três registros, assim considerados por serem nominadores que promovem "furo" - tal como no "Eu sou o que sou" de Jeová em resposta 
a Moisés, uma vez que essa nominação, não remetendo a qualquer simbolização, faz a linguagem se "desarrumar". Nominação, então, é anúncio/recusa, presença/ausência. Nesse sentido: "pode ser o mestre, no nível da função, um dos nomes do pai?”.

Por um lado, diz o autor, ao homem-mestre encarnado lhe falta o princípio da ex-sistência e ele parece muito mais um arauto da lei, que nomeia sem fazer furo por nomear o que já tem nome, por não fazer mais que repetir o ato de nomear, num esforço de demonstrar-se à altura de um nomeador per si. Porém, como o repetido não se repete, tal impossibilidade torna o mestre escravo da repetição/tentativa de manutenção do idêntico. Portanto, o mestre, ou melhor, seu ato fracassa e "sua impostura o persegue".

Por outro lado, Pereira aposta que se pode chegar a outras conclusões por um caminho semelhante ao que fez Lacan, que atribui a Édipo o estatuto de Nome-do-Pai. Passando por articulações de ideias em torno da inacessibilidade do nome de deus (Moisés e o monoteísmo) e por santo Agostinho, chega à idéia de que, mesmo movendo-se através de repetições mal-feitas do nome impronunciável de deus, o mestre pode guardar alguma semelhança àquele que santo Agostinho denomina mestre per si. Sendo assim, "somos todos mestres nomeantes, como se supõe que deus assim seja.... apenas isso já nos posiciona como impostores, não por nos fazer deuses, mas por nunca elevar a nossa transmissão à condição de equivalência daquilo que supomos que deva ser transmitido" (p. 92). Porém, é justamente no caráter de fracasso de nossas repetições que reside nossa salvação, pois ele induz à suplência. Se, por um lado, os mestres humanos são "mestres não-todos nomeantes" pois são nomeadores "justo naquilo que escapa ou que cai da dissimetria entre a repetição e o suposto repetir" (p. 93) -, por outro lado, são também nomeantes, nesses instantes em que algo de si, para além do significante-mestre que aprisiona, faz furo, ao se fazerem, eles mesmos, suplentes, descartáveis, provisórios. Nesses momentos, seus atos podem funcionar como um dos nomes do pai, fazendo-os deixar de ser meros repetidores, ganhando a "função de nominação justo no que excede à sua conduta, justo naquilo que empresta ao seu corpo e à sua palavra" (p. 93).

No caminho em direção ao mestre que propõe, Pereira faz ainda mais uma análise, a invenção do mestre, inscrita num complexo que se constitui a partir da precocidade e incompletude do animal humano que o leva, para além do orgânico, à pulsão. Sendo a pulsão algo que visa o enlaçamento do outro como objeto desnaturalizado, de tal 
enlaçamento faz parte a demanda de educação, de direção, de significação. Daí surge uma "pista sobre uma possível genealogia do mestre e de suas vicissitudes quanto à constituição humana" (p. 97) que o autor se propõe a seguir: tomar esse outro no lugar antropológico de educador, guia e nutriz. Para tal empresa e sob esse prisma, analisa algumas obras de autores que se empenharam em dizer algo sobre o que viria a ser um mestre, entre eles: Gusdorf, Rancière e Imbert. ${ }^{3}$ Deles, Pereira pinça algumas idéias para construir aquele que denomina o mestre polissêmico.

O fio comum encontrado nos autores examinados é que suas teorias subtraem o mestre - autêntico (Gusdorf), emancipador (Rancière) ou simbólico (Imbert) - de sua própria impostura, direção que Pereira também segue, porém, sem apelar a idealizações. Ao contrário, ao propor o mestre nos quatro discursos, movimenta-se no sentido de lhe restituir sua dimensão de impossibilidade. É no discurso que o sujeito tenta ser compreendido pelo outro e tem a confirmação de que tal coisa é impossível, uma vez que todo discurso é movido por uma verdade, e, como diz Lacan, a verdade não se diz toda. Portanto, o mestre dos quatro discursos não pode ser um mestre da certeza nem da univocidade, como demonstra a polissemia do mestre e, portanto, não pode estar amalgamado ao pai e nem a deus.

Pereira toma a "teoria dos quatro discursos" de Lacan para melhor 
operar a necessária disjunção entre pai, mestre e deus. Porém, indo além daquele, propõe que o mestre - todo aquele que tem por função "amestrar" o outro - se enuncia não somente no discurso chamado "do mestre", mas também nos outros três - da universidade, da histérica e do analista. Para tanto, é necessário que não se fixe em seu discurso, pois a fixação é sua condenação ao desmentido, sua derrocada. Nesse sentido, é preciso abandonar uma certa posição "perversa" do assemelhar-se ao pai e a deus. Também não pode se fixar na posição "paranóica" do discurso universitário sem que sua impostura seja denunciada pelo escárnio de nunca estar à altura do mestre dos textos que consulta. Tampouco pode demorar-se na posição "neurótica" do discurso do desejo insatisfeito da histérica que oscila entre autorizar e desautorizar seus mestres. Já no discurso do analista, não pode se fixar, em primeiro lugar, em função da própria estrutura desse discurso que tem como agente o objeto causa de desejo e a posição de causa de desejo do sujeito chega a ser insuportável, por ser o objeto, como diz Lacan, em primeira e última instância, um dejeto. Em segundo lugar, porque o discurso do analista é o avesso do discurso do mestre, que vem a ser o discurso como tal no qual o agente é a subjetividade/eu. Enquanto este agencia o discurso a partir de um ordenamento da lei - uma vez que "acredita" que tudo deve a ela se submeter - aquele introduz "uma forma radicalmente nova nas relações da cultura" (p. 134) ao dirigir-se ao outro do discurso como sujeito, ou seja, deslocando-se dos lugares de ordenamento (discurso do mestre), do saber (discurso da universidade) e da queixa/denúncia (discurso da histérica). E finalmente porque, à diferença dos demais, o discurso do analista faz sua aparição no momento em que um dos outros, em função de sua impossibilidade intrínseca, falha.

É no discurso do analista que nosso autor vê o mestre mais próximo do que propõe, superando uma aparente contradição seguindo a via do significante, alinhando a ele: ato, nominação, furo real do simbólico, pura diferença, suplência, provisório. Nessa posição o mestre demite-se "de sua pretensão simbólica, de seu excesso de sentido, em favor de uma ação tida no nível de uma intervenção lógica” (p. 141). Enfim, a saída encontrada e declarada pelo autor para o mestre é: “o mestre só o é provisoriamente." (p. 143).

Retomando Totem e tabu, Pereira aponta o caráter coletivo instaurado nas origens da sociedade fraterna convivendo com o contraponto do "um a um" que revela diferenças. Enquanto estas dizem respeito à apropriação de cada um, do nome do pai, a igualdade só se dá em 
função da submissão à lei, ou seja, a irmandade se define pela comunhão da castração. Porém, a igualdade entre irmãos termina onde começa e, no coletivo, as desigualdades passam a se manifestar a partir de diferenças. Desigualdades que são o alvo das revoluções da virada moderna que tentaram liquidá-las através da civilização da arbitrariedade paterna, presente nas sociedades pré-modernas.

Uma das conseqüências dessas revoluções teria sido o advento da ordem republicana que instaura a universalização da escola laica, gratuita e obrigatória. Nessa instauração, pode-se ver como a escola, assim como qualquer instituição, subtrai algo da paternidade em nome de outro algo que a ultrapassa. Porém, e esta idéia compõe a tese do autor, tal subtração "é constituinte do humano na cultura e não exatamente um trunfo do ingresso do homem na modernidade" (p. 148). É verdade que a imagem do pai se modificou, entre outras coisas porque, ao dividir com o estado a responsabilidade da educação de seus filhos, demitiu-se de uma autoridade nele centrada. Porém, não se pode buscar as causas dessa mudança na esteira de muitos dos estudos que se ocuparam em analisar a deposição do pai na modernidade estabelecendo um conformismo entre o declínio de uma sociedade do pai e a contemporaneidade. Ao contrário, sua leitura de Freud o leva a afirmar que "a sociedade não se tornou 'sem pai'; ela nunca o teve senão sob a forma de uma nostalgia, qual seja, a nostalgia da vontade do par" (p. 151).

A questão é entender o quanto a passagem para a modernidade e a aparente substituição do discurso religioso pelo científico insuflou no homem recém-inventado a pretensão de ser capaz de conduzir o próprio destino e de domar e racionalizar a natureza a tal ponto de pretender e "crer racionalmente" no triunfo sobre a morte - chegar à perfeição de deus - quando, por outro lado, a ruptura com a tutela divina colocou os "pequenos deuses multiplicados" diante da percepção de sua condição de faltosos e precários, tal como após o assassinato mítico do pai. Nessa direção, Pereira afirma: "esse mito fundacional, no seu sentido estrito, diz muito mais sobre a emergência de uma sociedade moderna do que de uma sociedade geral, originária e genuína." Porém, pode-se tirar desse modelo um "pressuposto fundamental: como os ideais de democracia, de liberdade e de república estão intimamente ligados à castração, à insuficiência e à morte” (p. 155) e, nesse sentido, apontam a revivescência do drama dos primeiros revoltosos, como destino dos homens. Assim, pode-se afirmar como ilusão, a místi- 


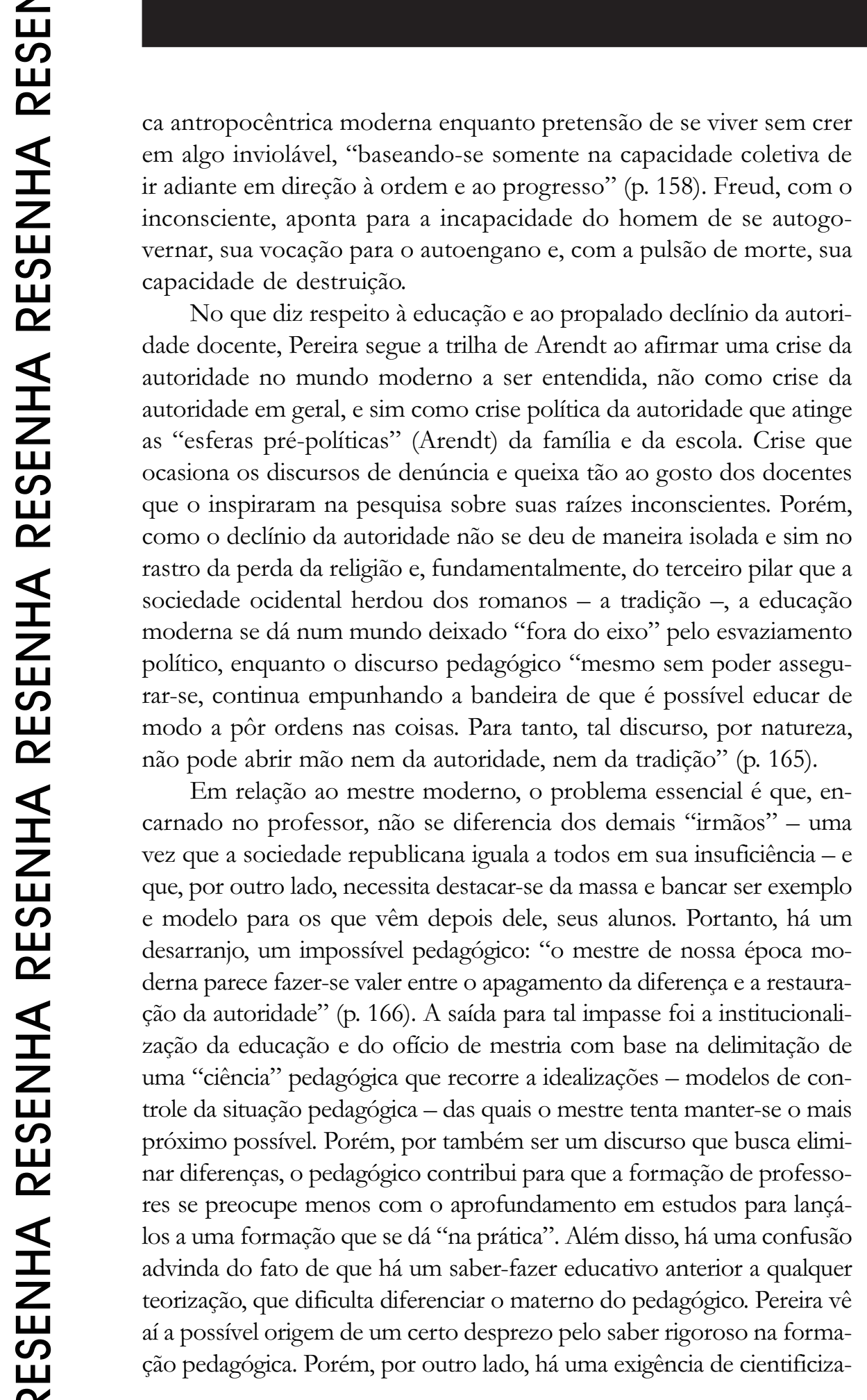


ção do saber-fazer materno, de submetê-lo à mística moderna, que leva a "maternagem" - "último reduto de empirismo consentido e jubilado pela humanidade" - a perder sua força. Uma das consequências dessa cientifização se faz notar numa "suavização irrefletida da transmissão da lei por parte do discurso pedagógico", "em favor de uma moralidade outra, mais 'humana', mais igualitária, mais fraterna” (p. 177). Essa moralidade humanista também é imposta à ciência pelo discurso pedagógico, que faz desta uma doutrina construída das partes subtraídas às epistemologias dos saberes que requer, sem interrogá-las. A pedagogia é, assim, uma "proscratinação" da constituição de uma epistemologia própria e situa-se "entre um sintoma e uma esperança: o sintoma de fazer advir em si mesma o impossível de amestrar, de curar, de educar; e a esperança de elevar o discurso materno, inclusive no que esse guarda de feminização do magistério à condição de eminentemente científico" (p. 178). Aqui o autor vê uma perda: perde-se o considerar o discurso pedagógico e a "maternagem" por ele engendrada como resposta ao impossível. Dito de outra forma, o discurso pedagógico perde por não colocar o impossível como seu fundamento, ao lado das cientifizações que requer. Impossível de que falam as queixas sobre as dificuldades de unir prática e teoria, uma vez que a oposição entre ambas diz respeito à impossibilidade de a palavra recobrir a "coisa".
Nesse sentido, Pereira defende que a pedagogia deveria criar uma episteme "circunstancial ou prática, voltada ao acontecimento, à insurreição cotidiana, às regularidades de saber, próprias do seu exercício... Teríamos, então, no que concerne ao corpus pedagógico, uma moral própria, 'orientada para a ética'. Isso faria advir sua substância ética que, ... menos preocupada com o a priori, se daria na práxis; e, menos preocupada com a razão, induziria ao desejo.” (p. 184).

Propõe, então, algo que vai ao revés da tradição racionalista: que a "maternagem" possa "se traduzir como uma epistemologia da prática ou da circunstância" (p. 185). Para tanto, teria que, minimamente, sintetizar a racionalidade e a circunstância enquanto causas, elevando "seus elementos e seus gestos à condição de contingentes tanto quanto já os eleva à condição de científicos” (p. 185). Dessa maneira, poderia ser admitida como "substância ética da pedagogia", no mesmo sentido que o inconsciente o é para a psicanálise e a mais-valia para o marxismo. Como episteme, poderia acabar com a queixa interminável advinda do impossível do ato de educar, que marca os mestres fabricados pela pedagogia na forma de uma nostalgia de não haver "uma teoria circunstancial que seja equivalente a uma prática experimentada; também de não haver um saber teórico que possa ser articulado às teorias das situações singulares e microfísicas do cotidiano pedagógico" (p. 186). 


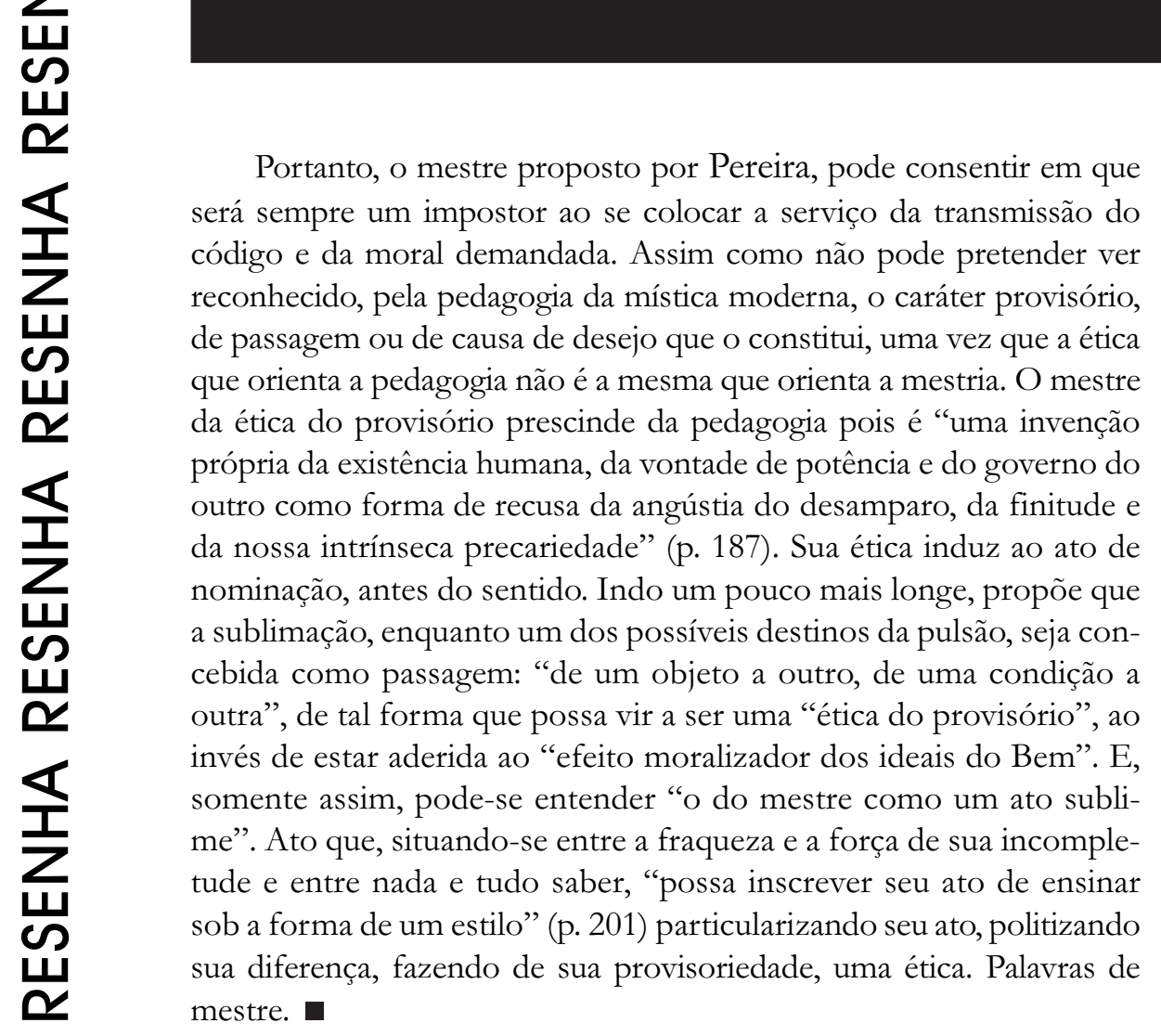

\section{REFERÊNCIAS BIBLIOGRÁFICAS}

Gusdorf, G. (2003). Professores para que?: para uma pedagogia da pedagogia. São Paulo: Martins Fontes.

Rancière, J. (2002). Mestre ignorante: 5 lições sobre a emancipação cultural. Belo Horizonte, MG: Autêntica.

Imbert, F. (2001). A questão da ética no campo educativo. Petrópolis, RJ: Vozes.

\section{NOTAS}

\section{$13 \mathrm{x} \bar{\Phi} \mathrm{x}$}

2 Operação de linguagem que possibilita à criança substituir, recalcar, o primeiro significante introduzido na simbolização (significante do desejo da mãe através do qual se fazia um com ela) por um outro, o Nome-do-Pai, que passa a designar o objeto fundamental do desejo, qual seja, o desejo da mãe naquilo que se refere ao falo enquanto significante de desejo 


\section{Resenha}

3 Gusdorf, G. (2003), Rancière, J. (2002), Imbert ,F. (2001).

4 O termo "maternagem", inspirado em idéia de Eliane Marta Teixeira Lopes em trabalho sobre a questão da feminização do magistério, é utilizado pelo autor para fazer notar a pregnância do discurso "humano" e "religioso" no discurso pedagógico. A "maternagem" emerge na ordem pedagógica, como resultado da dispersão discursiva gerada pelo declínio político da autoridade, tendo em seu bojo princípios "domésticos" de um saber-fazer educativo não interrogado por um saber-teórico. Porém, a pedagogia moderna, a partir da necessidade de desvendar seu "outro", passa a exercer pressão no sentido de sua cientifização.

maciafogaca2001@yahoo.com.br

Recebido em marco/2009.

Aceito em maio/ 2009. 